\title{
Bisphenol A levels in bowel endometrioma diagnosed serums: A case control study
}

\author{
Filiz Ardic ${ }^{1}$ Humeyra Celik ${ }^{2}$, ${ }^{(D)}$ Huseyin Yesilyurt ${ }^{3}$, ${ }^{(D)}$ Serap Mutlu Ozcelik Otcu ${ }^{4}$ \\ ${ }^{1}$ Department of Obstetrics and Gynecology, A $\breve{g r}$ Patnos State Hospital, A $\breve{g r l}$, Turkey \\ ${ }^{2}$ Department of Physiology, Bolu Abant Izzet Baysal University, School of Medicine, Bolu, Turkey \\ ${ }^{3}$ Department of Obstetrics and Gynecology, Ankara City Hospital, Ankara, Turkey \\ ${ }^{4}$ Department of Obstetrics and Gynecology, University of Health Sciences, Gazi Yaşargil Training and Research Hospital, \\ Diyarbakır, Turkey
}

\section{A BSTRACT}

Aim: To investigate the bisphenol A (BPA) levels, which may be a risk factor in the etiology of endometrioma, in patients diagnosed laparoscopically with endometrioma with and without bowel involvement.

Method: In the prospective cross-sectional case control study, 47 cases were included in the study, which were admitted to the gynecology and infertility services with and without bowel involvement endometrioma who were operated and diagnosed histopathologically. 43 patients were included in the control group. For serum BPA value, blood samples taken immediately before the operation were studied in laboratory. Patients and controls were compared with controls in terms of serum BPA values.

Results: The mean age of the patients was $35 \pm 2$ in the endometriosis group and $36 \pm 2$ in the control group which was and not statistically significant. There was no statistical difference between the patient and control groups in terms of menstruation periods. Serum BPA levels were significantly higher in the bowel involvement group compared to the non-bowel involvement group, as the distribution width was higher due to excessive values, and only 5 patients with bowel involvement did not reach statistically significant levels. Serum BPA level was $1084 \pm 1132 \mathrm{ng} / \mathrm{L}$ in the endometriosis group and $269 \pm 99 \mathrm{ng} / \mathrm{L}$ in the control group which was statistically significant $(p<0,001)$.

Conclusions: BPA levels were showing very wide range especially in the patient group. Serum BPA levels was statistically significantly higher in the endometrioma group compared to the control group. Therefore, in the etiology of endometriosis BPA may take a definite place.

Key words: Endometrioma, endometriosis, intestine, bowel, bisphenol-A.

Humeyra Celik

Department of Physiology, Bolu Abant Izzet Baysal University, School of Medicine, Bolu, Turkey

E-mail: humeyra.colaker@gmail.com

Received: 2021-06-23 / Revisions: 2021-10-14

Accepted: 2021-10-24 / Published online: 2022-01-01

\section{Introduction}

Endometriosis is a chronic inflammatory disease characterized by the endometrial gland and stroma outside the endometrium [1]. Its clinical symptoms are dysmenorrhea, dyspareunia, non-cyclic pelvic pain, and subfertility and cause 30-50\% infertility and $10-15 \%$ morbidity in premenopausal reproductive women [2]. Even if endometriosis is a benign gynecological disease, it carries a risk of epithelial ovarian cancer [3]. Although endometriosis is classified as genital and extragenital [4], the most common position of extragenital endometriosis is the bowels $[5,6]$. 
Where there is still conflicting information about its prevalence, pathogenesis, natural course, and optimal treatment, and today it is believed that environmental toxins may also be one of its pathogenesis.

Environmental toxins that induce the dysregulation of hormone systems that regulate reproductive, cardiovascular, neurological and immune processes in humans are called endocrine-disrupting chemicals (EDC) [7]. People exposed to EDCs have been shown to have an increased risk of developing diseases such as cancer, diabetes, obesity, infertility [812]. Bisphenol A (BPA); is one of the commonly used EDCs [13]. 70\% of the produced BPA is used in polycarbonate plastics and $25 \%$ in epoxy resins [14], polycarbonates are included in the structure of various plastic products such as feeding bottles, tin cans, and water bottles [15]. Epoxy resins, on the other hand, are used for coating the inner surface of metal cans used in the packaging of food and beverages and different types of food transport containers. If the process does not occur correctly in constructing these packaging materials, the migration of BPA-type resins and reaction products to food is formed [16]. Considering that packaged convenience foods are consumed very intensively in our age, studies on substances that migrate from packaging materials to food become important for food safety and human health.

Due to its estrogen (E2)-like structure, BPA shows estrogenic effects by binding to $\alpha$ receptors and weakly $\beta$-estrogen receptors (ER) in vivo and in vitro environment [17]. Although BPA binds to nuclear estrogen receptors with less affinity than $17 \beta$-estrogen (E2), it binds to non-nuclear estrogen receptors with similar affinity as E2 [18]. BPA could act as an anti-estrogen that blocks the estrogenic response by competing with endogenous E2 [19] and showing an antiandrogenic effect by binding directly to androgen receptors blocking endogenous androgen activity $[19,20]$.

In recent years, it has been known that BPA can negatively affect the endocrine system even at lower doses [21]. BPA taken by various means is metabolized in the liver glucuronidation pathway. BPA loses its estrogenic effect when sulfated. The approximate half-life of BPA is 6 hours, and almost all of it is excreted in urine within 24 hours. Although rapidly metabolized, BPA could accumulate in tissues for a long time and participate in the conjugation deconjugation cycle [22]. It is believed that BPA is exposed to toxic effects, especially during the fetal and neonatal period, when liver detoxification enzymes are not yet developed, and its effects are revealed through this period [23].

One of the theories put forward to explain the etiology of endometriosis, the cause of which is not precisely known, is induction theory. This theory suggests that some exogenous and endogenous hormonal and biological factors cause the transformation of undifferentiated cells into endometrium tissue [24]. In vitro studies have said that ovarian surface epithelium has the potential to undergo transformation to form endometriotic lesions in response to estrogen [25]; prenatal exposure of mice to BPA can reveal an EM-like phenotype in female offspring [26]. The demonstration that BPA exposure causes endometriosis-like lesions has led to the hypothesis that BPA may play a role in endometriosis pathogenesis. Therefore, we wanted to shed light on whether BPA can be included in endometrioma pathogenesis by examining the serum levels of BPA, which is an environmental toxin patient with and without bowel involvement. 


\section{Materials and methods}

\section{Study design}

For this study, Clinical Ethics Committee approval with the decision number 120/2017 was obtained from Health Sciences University Ankara Dr. Zekai Tahir Burak Women's Health Health Application and Research Center. Data were obtained at gynecology clinics of the same hospital, carried out from 2017 to 2018.

A total of 90 patients, 47 female patients and 43 healthy women aged 29-38, were included in the study according to inclusion and exclusion criteria (Table 1). The control group was created from women who were admitted to our hospital for routine follow-up or pap smear. The endometrioma group was formed from people who were diagnosed with endometrioma during laparoscopy or laparotomy and reported endometrioma as a result of the pathological examination in their material.

Table 1. Inclusion and exclusion criteria.

\begin{tabular}{|c|c|}
\hline Inclusion criteria & Exclusion criteria \\
\hline $\begin{array}{l}\text {-Being between the } \\
\text { ages of } 29-40 \\
\text {-Getting written } \\
\text { consent }\end{array}$ & $\begin{array}{l}\text {-Taking any hormonal } \\
\text { medication in the last } 6 \\
\text { months } \\
\text {-Having applied assisted } \\
\text { reproductive techniques in } \\
\text { the last } 6 \text { months } \\
\text {-Endometrioma / cyst } \\
\text { detected in USG } \\
\text {-Having dysmenorrhea / } \\
\text { dyspareunia } \\
\text {-Having } \\
\text { irregularity } \\
\text { BMI > 35 }\end{array}$ \\
\hline
\end{tabular}

The information of patients was obtained by conducting a face-to-face interview. Body mass index was calculated by measuring height and weight during the hospitalization of patients. The cases in the follicular phase of the menstrual cycle and at the end of menstruation were included in the study. Dyspareunia and dysmenorrhea were questioned. New onset and non-recurrent pains were not considered dyspareunia. Patients who described the new onset of dysmenorrhea or pain for other reasons were not included in the group. All patients in control and endometrioma groups were married. One patient in the endometrioma group, despite being married for one year, did not have children and was accepted as infertile. Since this patient did not receive any hormonal therapy, the patient was included in the endometrioma group.

\section{ELISA}

After verbal consent was obtained from all of the patients in the study group, 10 ccs of venous blood were collected at the end of 8 hours of fasting to evaluate serum BPA levels on the morning of the operation. The blood taken was immediately taken into a glass tube after being centrifuged at $3000 \mathrm{rpm}$ for 20 minutes. The tubes were paraffinized and stored at $-80^{\circ} \mathrm{C}$ without exposure to any plastic material and sunlight. BPA levels in serum were analyzed with the sandwich ELISA detection method following the instructions prepared by the kit manufacturer (Pars BioChem NanjingG Pars BioChem CO, LTD). In ELISA analysis, samples were read in a Rayto microplate RT $2100 \mathrm{C}$ reading device. The kits have a $50 \mathrm{ng} /$ L sensitivity, and the BPA threshold value was accepted as 150-4000 ng / L.

\section{Statistical analysis}

The numerical data measured were presented as mean and standard deviation (SD), median (median), minimum and maximum values. Kolmogorov-Smirnov and Shapiro-Wilk tests were used to determine whether the numerical values obtained from the measurement were compatible with the normal distribution. Since numerical values did not conform to the normal distribution, data belonging to independent groups were compared using the Mann- 
Whitney U test. Non-parametric Spearman correlation analysis was used for correlations between numerical values. Nominal or ordinal data obtained by census were presented as numbers and percentages. In statistical analysis, p value below 0.05 was considered statistically significant.

\section{Results}

47 age-matched female patients with endometriosis and 43 healthy women were included in the study as the endometrioma group and control group. The mean age of the endometrioma and control groups was $35 \pm 2$ years, and no statistical difference was found between them ( $p=0.127$ ) (Table 2) maximum: 236-4450 ng / L), especially in the endometrioma group (Table 2).

When patients with endometriosis with and without bowel involvement were compared; it was observed that there was no significant difference between the two subgroups in terms of age, menarche age and duration of menstruation ( $p>0.05$ for each) (Table 3). However, endometrioma size was found to be significantly higher in patients with bowel involvement compared to those without involvement ( $p=0.041)$ (Table 3).

Serum BPA levels were observed to be very high in the group with bowel involvement compared to the non-involvement group (median values; $1805 \mathrm{ng} / \mathrm{L}$ and $464 \mathrm{ng} / \mathrm{L}$,

Table 2. Comparison of the characteristic features between the endometrioma and control groups.

\begin{tabular}{|c|c|c|c|c|c|}
\hline \multirow{2}{*}{ Parameters } & \multicolumn{2}{|c|}{$\begin{array}{c}\text { Endometrioma group } \\
(n=47)\end{array}$} & \multicolumn{2}{|c|}{$\begin{array}{c}\text { Control group } \\
(n=43)\end{array}$} & \multirow[t]{2}{*}{ P value } \\
\hline & Mean \pm SD & $\begin{array}{c}\text { Median } \\
(\text { Min-Max) }\end{array}$ & Mean \pm SD & $\begin{array}{c}\text { Median } \\
(\text { Min-Max) }\end{array}$ & \\
\hline Age (Year) & $35 \pm 2$ & $35(29-38)$ & $35 \pm 2$ & $35(32-38)$ & 0,127 \\
\hline Menarche age (Year) & $12 \pm 1$ & $13(11-15)$ & $13 \pm 1$ & $13(11-15)$ & 0,001 \\
\hline Menstruation (Day) & $6 \pm 2$ & $6(4-9)$ & $6 \pm 1$ & $6(4-8)$ & 0,739 \\
\hline Bisphenol A (ng/L) & $1084 \pm 1132$ & $488(236-4450)$ & $269 \pm 99$ & $233(155-505)$ & $<0,001$ \\
\hline
\end{tabular}

Menarche ages of the endometrioma group was found to be significantly lower than the control group ( $\mathrm{p}=0.001$ ) (Table 2 ). No statistically significant difference was found between the endometrioma and control groups in terms of menstrual periods ( $6 \pm 2$ days and $6 \pm 1$ days, respectively, $p=0.739$ ) (Table 4$)$.

Serum human BPA levels of the endometrioma group (1084 $\pm 1132 \mathrm{ng} / \mathrm{L})$ were found to be significantly higher than the control group (269 $\pm 99 \mathrm{ng} / \mathrm{L})(\mathrm{p}<0.001)$ (Table 2). BPA levels showed a very wide range (minimum- respectively), it was observed that the difference between the two groups could not reach a statistically significant level since because the distribution was too high due to extreme values and there were patients only 5 with bowel involvement (Table 3). However, the size of endometrima was found to be significantly higher in patients with intestinal involvement compared to those without involvement ( $p=0.041$ ) (Figure 1).

A weak negative correlation was found between serum BPA level and patient age in the 
Table 3. Comparison of the variables for endometrioma group with and without bowel involvement.

\begin{tabular}{|l|c|c|c|c|c|}
\hline \multirow{2}{*}{ Parameters } & \multicolumn{2}{|c|}{$\begin{array}{c}\text { Bowel Involvement (-) } \\
(\mathbf{n = 4 2})\end{array}$} & \multicolumn{2}{c|}{$\begin{array}{c}\text { Bowel Involvement (+) } \\
(\mathbf{n = 5})\end{array}$} & \multirow{2}{*}{ P Value } \\
\cline { 2 - 6 } & Mean \pm SD & $\begin{array}{c}\text { Median } \\
\text { (Mean-Max) }\end{array}$ & Average \pm SD & $\begin{array}{c}\text { Median } \\
\text { (Min-Max) }\end{array}$ & \\
\hline Age (Year) & $35 \pm 2$ & $35(29-38)$ & $36 \pm 2$ & $36(33-37)$ & 0,429 \\
\hline Menarche age (Year) & $12 \pm 1$ & $13(11-15)$ & $12 \pm 1$ & $12(11-13)$ & 0,603 \\
\hline Duration of menstruation (Day) & $6 \pm 2$ & $6(4-9)$ & $5 \pm 1$ & $6(4-7)$ & 0,390 \\
\hline Endometrioma (mm) & $7 \pm 1$ & $8(5-9)$ & $8 \pm 1$ & $8(8-9)$ & $\mathbf{0 , 0 4 1}$ \\
\hline Bisphenol A (ng/L) & $978 \pm 1071$ & $464(250-4450)$ & $1973 \pm 1366$ & $1805(236-3950)$ & 0,190 \\
\hline
\end{tabular}
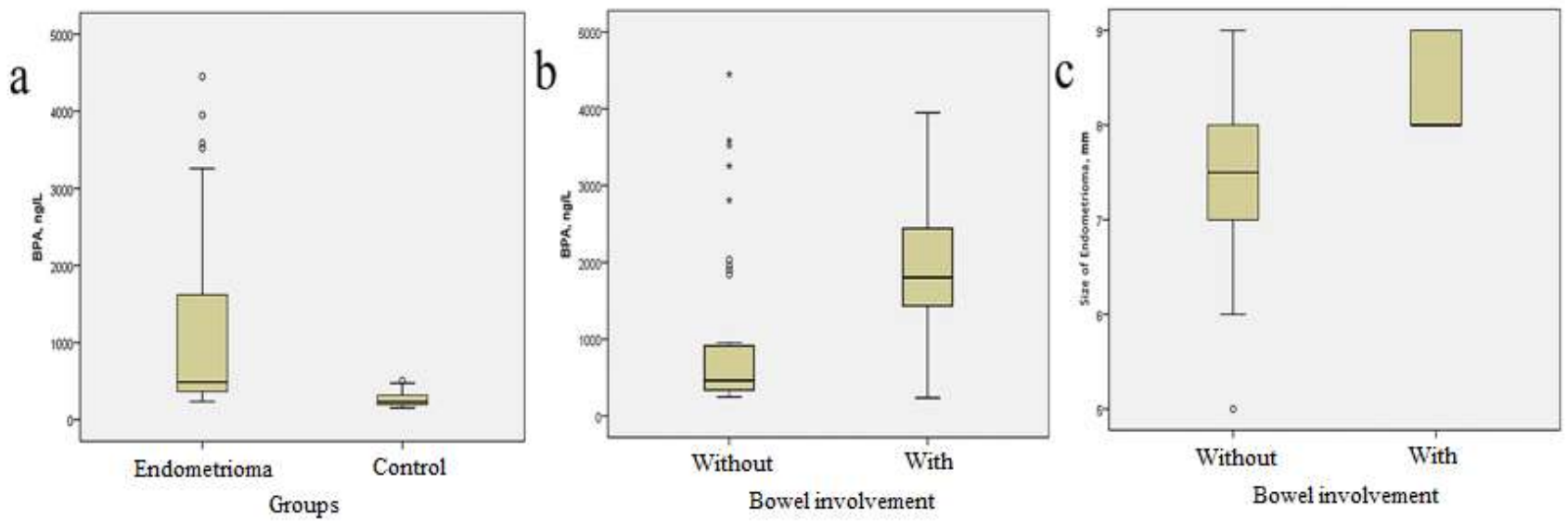

Figure 1. a) Graph of serum bisphenol A values of endometrioma and control groups. b) Graph of serum bisphenol A values of endometrioma group with and without bowel involvement. c) Endometrioma size graph of the endometrioma group with and without intestinal involvement.

endometrioma group ( $\mathrm{r}=-0,307 ; \quad p=0,036)$ (Tablo 4). However, there was no significant correlation between BPA and age in the control group ( $\mathrm{p}=0,413)$. No significant correlation was found between serum BPA levels and menarche age, menstrual duration, and endometrioma size in both the endometrioma group and the control group $(p>0,05)$ (Table 4$)$.

\section{Discussion}

In the world, 10-15\% of women of reproductive age are affected by endometriosis, and endometriosis is considered a significant cause of morbidity [27]. Considering the demographic characteristics, it is known that endometriosis is diagnosed in the reproductive period [28] and that early menarche age is a risk factor for endometriosis [29], and that menstrual bleeding is prolonged. In the study, the average age of endometrioma group with endometriosis being in the reproductive period and not being different from controls [30] and the early menarche age compared to controls $[30,31]$ are consistent with the literature. The information that the duration of menstrual bleeding is long in patients with endometriosis [32] is not compatible with the result of the study, but similar studies are encountered when evaluated daily (6 days) [33]. 
Table 4. Spearman's correlation coefficients ( $r$ ) and significance levels (p) between serum Bisphenol A level and other variables in the endometrioma and control groups.

\begin{tabular}{|l|l|l|c|c|c|c|}
\hline \multicolumn{2}{|l|}{ Groups } & Age & Menarche age & $\begin{array}{c}\text { Duration of } \\
\text { menstruation }\end{array}$ & $\begin{array}{c}\text { Size of } \\
\text { endometrium }\end{array}$ \\
\hline \multirow{2}{*}{ Endometrioma } & \multirow{2}{*}{ Bisphenol A } & $\boldsymbol{r}$ & $-0,307^{*}$ & 0,030 & $-0,206$ & 0,070 \\
\cline { 3 - 8 } & & $\boldsymbol{p}$ & $\mathbf{0 , 0 3 6}$ & 0,840 & 0,165 & 0,641 \\
\hline \multirow{2}{*}{ Control } & \multirow{2}{*}{ Bisphenol A } & $\boldsymbol{r}$ & 0,128 & 0,027 & $-0,012$ & - \\
\cline { 3 - 8 } & & $\boldsymbol{p}$ & 0,413 & 0,862 & 0,939 & - \\
\hline
\end{tabular}

Many risk factors have been identified for endometriosis, such as genetics, age, race, obesity, exposure to the hormone, and environmental conditions. BPA is also considered one of the most widely used environmental factors today, and that can be considered a risk factor in the formation of endometriosis. Due to the E2-like nature of BPA, it binds to $\alpha$-receptors in vivo and in vitro and weakly to $\beta$-estrogen receptors (ER), demonstrating estrogenic effects [17]. Although BPA binds to nuclear estrogen receptors with lower affinity than $17 \beta$-estradiol (E2), it binds to non-nuclear estrogen receptors with similar affinity to E2 [18]. BPA could act as an anti-estrogen that blocks the estrogenic response by competing with endogenous E2 and binding directly to androgen receptors [19], blocking endogenous androgen activity and showing an antiandrogenic effect $[19,20]$. In recent years, it has been known that BPA can negatively affect the endocrine system even at low doses [21]. In our study, serum BPA levels were significantly higher, although there was an extensive distribution in the endometrioma group. Although a weak negative correlation was observed between serum BPA levels and patient age in the endometrioma group, no correlation was found between serum BPA levels and menarche age, menstrual duration, and endometrioma size in the endometrioma group and the control group. The detection of the high amount of BPA in the serum of patients with endometriosis in accordance with the study of Cobellis et al. [34] suggests that BPA is involved in the pathophysiology of endometriosis. The difference of between Cobellis et al. and the present study is BPA analysis method. Cobellis et al. assessed serum BPA levels by chromatography but our method is ELISA.

The area that extragenital endometriosis most commonly observed is the bowels [6] and 3.8$37 \%$ of patients with endometriosis have bowel endometriosis [35]. As the ethiopathogenesis of intestinal endometriosis is multifactorial (retrograde menstruation, coelomic metaplasia, lymphatic dissemination, etc.) [36], the bowel contact of endocrine disrupting chemicals taken with food gives BPA a position in terms of pathogenesis. In our study, patients with endometriosis with and without intestinal involvement were compared; the size of endometrioma was significantly larger in patients with bowel involvement compared to those without involvement. Serum BPA levels were observed to be very high in the group with bowel involvement compared to the group 
without involvement (median values; $1805 \mathrm{ng} /$ L and $464 \mathrm{ng} / \mathrm{L}$, respectively), measurement of extreme values, too much distribution width, and the presence of only five patients with bowel involvement caused the difference between the two groups to not reach a statistically significant level. The high presence of BPA, which enters the body with food intake, in those with intestinal involvement is significant in terms of the place where BPA is absorbed into the body. Especially for the endometrioma group with bowel endometriosis, avoiding BPA may affect the course of the disease. Our study is original in terms of showing bowel involvement and serum BPA values.

BPA taken in various ways is mainly metabolized in the liver glucuronidation pathway and loses its estrogenic effect when BPA is sulfated. The half-life of BPA is 6 hours, and although it is rapidly metabolized, BPA can accumulate in tissues for a long time and be included in the conjugationdeconjugation cycle. Although almost all of the BPA is excreted in the urine in 24 hours [22], high urinary BPA levels in patients diagnosed with laparoscopic endometriosis [37], and significantly higher total urinary BPA levels in patients diagnosed with non-ovarian endometrioma [38] indirectly support the results of our study. On the other hand, there are other studies in the literature in which the urinary BPA values in endometriosis were examined, and no significant results were obtained [39, 40]. However, the evaluation of these studies in patients diagnosed with endometriosis radiologically limited the discussion. Studies showing how exposure to BPA causes changes in the organism shed light on the pathophysiology of BPA endometriosis. In the study in which BPA was given to an endometriotic animal model created by injecting uterine tissue into the pelvis, and its effects were examined, it has been shown that BPA increased distal lesion volumes (300 and 900 ppm BPA), increased the number of atretic and dead follicles (30, 300 and 900 ppm BPA), activate estrogen receptor genes and disrupt ovarian functions [41]. In another study investigating the effects of BPA in the in vitro endometriosis model, it was reported that BPA showed agonistic activity against estrogen receptor alpha and beta [42]. In another study conducted to investigate the role of BPA in the pathophysiology of endometriosis, it was observed that high urinary BPA levels and high thiobarbituric acid-reactive products were associated with each other in women diagnosed with endometriosis. It was stated that BPA could achieve its effects by increasing oxidative stress in the formation of endometriosis [43]. Since liver detoxification enzymes have not developed yet, it suggests that exposure to the toxic effects of BPA, especially in the intrauterine and neonatal period, reveals the effects of BPA through this period [44]. It has been determined that BPA given to pregnant Balb-C mice starting from the 1 st day of pregnancy and up to the 7th postpartum day causes endometriosis-like structures in the adipose tissue surrounding the genital areas of the offspring. In addition, cystic ovary, cystic endometrial hyperplasia, atypical hyperplasia, and adenomatous hyperplasic structures were seen more in animals exposed to BPA than controls [26]. Although endometriosis is diagnosed in the reproductive period, the fact that the effects of BPA are shown as a result of chronic exposure and through estrogenic receptors does not change the fact that it creates the primary pathology at a very early stage of life. 
As a result of our study, endocrine disrupting chemicals have gained importance regarding the pathogenesis of endometriosis. The present study is a clinical study but should been supported the effects of BPA in experimental studies, besides it should be investigate that what is relationship between BPA and bowel endometriosis. Studies aimed at enlightening the pathogenesis of endometriosis could create new treatment options and prevent infertility and cancers due to endometriosis.

Funding: The author(s) received no financial support for the research, authorship, and/or publication of this article.

Conflict of Interest: The authors declare that they have no conflict of interest.

Ethical statement: Clinical ethics committee approval with the decision number 120/2017 was obtained from Health Sciences University Ankara Dr. Zekai Tahir Burak Women's Health Health Application and Research Center.

\section{Open Access Statement}

This is an open access journal which means that all content is freely available without charge to the user or his/her institution under the terms of the Creative Commons Attribution NonCommercial License (https://creativecommons.org/licenses/by/4.0/). Users are allowed to read, download, copy, distribute, print, search, or link to the full texts of the articles, without asking prior permission from the publisher or the author.

Copyright (c) 2021: Author (s).

\section{References}

[1]Matarese G, De Placido G, Nikas Y, et al. Pathogenesis of endometriosis: natural immunity dysfunction or autoimmune disease? Trends Mol Med. 2003;9(5):22328.
[2]Haydardedeoglu B, Zeyneloglu HB. The impact of endometriosis on fertility. Womens Health. 2015;11:619-23.

[3] Kim HS, Kim TH, Chung HH, et al. Risk and prognosis of ovarian cancer in women with endometriosis: a meta-analysis. Br J Cancer. 2014;110(7):1878-90.

[4]Nezhat C, Falik R, McKinney S, et al. Pathophysiology and management of urinary tract endometriosis. Nat Rev Urol. 2017;14(6): 359-72.

[5]Sourial S, Tempest N, Hapangama DK. Theories on the pathogenesis of endometriosis. Int J Reprod Med. 2014;2014:179515.

[6]Veeraswamy A, Lewis M, Mann A, et al. Extragenital endometriosis. Clin Obstet Gynecol. 2010;53(2):449-66.

[7]Kabir ER, Rahman MS, Rahman I. A review on endocrine disruptors and their possible impacts on human health. Environ Toxicol Pharmacol. 2015;40(1):241-58.

[8]Heindel JJ, Newbold R, Schug TT. Endocrine disruptors and obesity. Nat Rev Endocrinol. 2015;11(11):653-61.

[9]Sweeney MF, Hasan N, Soto AM, et al. Environmental endocrine disruptors: effects on the human male reproductive system. Rev Endocr Metab Disord. 2015;16(4):341-57.

[10] Costa EM, Spritzer PM, Hohl A, et al. Effects of endocrine disruptors in the development of the female reproductive tract. Arq Bras Endocrinol Metab. 2014;58(2):153-61.

[11]Chevalier N, Fenichel P. Endocrine disruptors: new players in the pathophysiology of type 2 diabetes? Diabetes Metab. 2015;41(2):107-15.

[12] Knower KC, To SQ, Leung YK, et al. Endocrine disruption of the epigenome: a breast cancer link. Endocr Relat Cancer. 2014;21(2):33-55. 
[13] Ballesteros G, Soledat P, Perez-Bendito D. Analytical methods for the determination of bisphenol A in food. J Chromatogram A. 2009; 1216(3): 449-69.

[14] Tsai W-T. Human health risk on environmental exposure to Bisphenol-A: a review. J Environ Sci Health $\mathrm{C}$ Environ Carcinog Ecotoxicol Rev. 2006; 24(2): 22555.

[15] Matsumoto A, Kunugita N, Kitagawa K, et al. Bisphenol A levels in human urine. Environ Health Perspect. 2003; 111(1): 101.

[16] García RS and Losada PP. Determination of bisphenol A diglycidyl ether and its hydrolysis and chlorohydroxy derivatives by liquid chromatography-mass spectrometry. J Chromatogr A. 2004; 1032(1-2): 37-43.

[17] Caserta D, Mantovani A, Marci R, et al. Environment and women's reproductive health. Hum Reprod Update. 2011; 17(3): 418-33.

[18] Alonso-Magdalena P, Laribi O, Ropero AB, et al. Low doses of bisphenol $A$ and diethylstilbestrol impair $\mathrm{Ca} 2+$ signals in pancreatic $\alpha$-cells through a nonclassical membrane estrogen receptor within intact islets of Langerhans. Environ Health Perspect. 2005;113(8): 969.

[19] Moriyama K, Tagami T, Akamizu T, et al. Thyroid hormone action is disrupted by bisphenol $\mathrm{A}$ as an antagonist. J Clin Endocrinol Metab. 2002; 87(11): 5185-90.

[20] Wetherill YB, Fisher NL, Staubach A, et al. Xenoestrogen action in prostate cancer: pleiotropic effects dependent on androgen receptor status. Cancer Res. 2005; 65(1): 5465.

[21]Lopez-Cervantes $\mathbf{J}$ and Paseiro-Losada P. Determination of bisphenol $\mathrm{A}$ in, and its migration from, PVC stretch film used for food packaging. Food Addit Contam. 2003; 20(6): 596-606.
[22]Lee J, Choi K, Park J, et al. Bisphenol A distribution in serum, urine, placenta, breast milk, and umbilical cord serum in a birth panel of mother-neonate pairs. Sci Total Environ. 2018; 626: 1494-1501.

[23] Ginsberg G and Rice DC. Does rapid metabolism ensure negligible risk from bisphenol A? Environ Health Perspect. 2009; 117(11): 1639.

[24] Vinatier D, Orazi G, Gosson M, et al. Theories of endometriosis. Eur $\mathrm{J}$ Obstet Gynecol Reprod Biol. 2001; 96(1): 21-34.

[25] Matsuura K, Ohtake H, Katabuchi H, et al. Coelomic metaplasia theory of endometriosis: evidence from in vivo studies and an in vitro experimental model. Gynecol Obstetric Invest. 1999; 47(1): 18-22.

[26] Signorile PG, Spugnini EP, Mita L, et al. Pre-natal exposure of mice to bisphenol A elicits an endometriosis-like phenotype in female offspring. Gen Comp Endocrinol. 2010; 168(3): 318-25.

[27] Vercellini P. Vigano P, Somigliana E, et al. 'Endometriosis: Pathogenesis and treatment', Nat Rev Endocrinol. 2014;10(5), 261-75.

[28] Tanbo T and Fedorcsak P. 'Endometriosisassociated infertility: aspects of pathophysiological mechanisms and treatment options', Acta Obstet Gynecol Scand. 2017;96(6) 659-67.

[29] Shafrir, A. L. Farland LV, Shah DK, et al. 'Risk for and consequences of endometriosis: A critical epidemiologic review'. Best Pract and Res Clin Obstet and Gynaecol. 2018; 51:1-15.

[30] Nnoaham KE, Webster P, Kumbang J, et al. 'Is early age at menarche a risk factor for endometriosis? A systematic review and meta-analysis of case-control studies', Fertil Steril. 2012; 98(3):702-12. 
[31] Matalliotakis I M, Cakmak H, Fragouli YG, et al. 'Epidemiological characteristics in women with and without endometriosis in the Yale series'. Arch Gynecol Obstet. 2008; 277(5): 389-93.

[32] Moini A, Malekzadeh F, Amirchaghmaghi $\mathrm{E}$, et al. 'Risk factors associated with endometriosis among infertile Iranian women'. Arch Med Sci. 2013 Jun 20;9(3):506-14.

[33] Darrow SL, Vena JE, Batt RE, et al. Menstrual cycle characteristics and the risk of endometriosis. Epidemiology. 1993;4(2):135-42.

[34] Cobellis L, Colacurci N, Trabucco E, et al. Measurement of bisphenol A and bisphenol B levels in human blood sera from healthy and endometriotic women. Biomed Chromatogr. 2009 ;23(11):1186-90.

[35]Redwine DB. Ovarian endometriosis: a marker for more extensive pelvic and intestinal disease. Fertil Steril. 1999;72(2):310-15.

[36] Yong PJ, Bedaiwy MA, Alotaibi F, et al. Pathogenesis of bowel endometriosis. Best Pract Res Clin Obstet Gynaecol. 2021;71:213.

[37] Rashidi BH, Amanlou M, Lak TB, et al. A case-control study of bisphenol $\mathrm{A}$ and endometrioma among subgroup of Iranian women. J Res Med Sci. 2017;22:7.

[38][38] Upson K, Sathyanarayana S, De Roos $\mathrm{AJ}$, et al. A population-based case-control study of urinary bisphenol A concentrations and risk of endometriosis. Hum Reprod. 2014 ;29(11):2457-64.

[39] Itoh H, Iwasaki M, Hanaoka T, et al. Urinary bisphenol-A concentration in infertile Japanese women and its association with endometriosis: A cross-sectional study. Environ Health Prev Med. 2007;12(6):25864.
[40]Buck Louis GM, Peterson CM, Chen Z, et al. Bisphenol $\mathrm{A}$ and phthalates and endometriosis: the Endometriosis: Natural History, Diagnosis and Outcomes Study. Fertil Steril. 2013;100(1):162-9.e1-2.

[41]Jones RL, Lang SA, Kendziorski JA, et al. Use of a Mouse Model of Experimentally Induced Endometriosis to Evaluate and Compare the Effects of Bisphenol A and Bisphenol AF Exposure. Environ Health Perspect. 2018;126(12):127004.

[42]Li Y, Perera L, Coons LA, et al. Differential in Vitro Biological Action, Coregulator Interactions, and Molecular Dynamic Analysis of Bisphenol A (BPA), BPAF, and BPS Ligand-ER $\alpha$ Complexes. Environ Health Perspect. 2018;126(1):017012.

[43] Peinado FM, Lendínez I, Sotelo R, et al. Association of Urinary Levels of Bisphenols $\mathrm{A}, \mathrm{F}$, and $\mathrm{S}$ with Endometriosis Risk: Preliminary Results of the EndEA Study. Int J Environ Res Public Health. 2020;17(4):1194. 